\title{
The Current States of Male Involvement on Family Planning and Factors Correlated with among Male Factory Workers in Bahir Dar City
}

\author{
Yeshareg Walle ${ }^{1}$, Zelalem Alamrew ${ }^{2, *}$ \\ ${ }^{1}$ Department of Family planning and child care, Family Guidance Association of Ethiopia, Bahir Dar city, Ethiopia \\ ${ }^{2}$ Department of Public Health, College of Medicine and Health Sciences, Bahir Dar University, Ethiopia \\ *Corresponding author: kzolam@gmail.com
}

Received September 25, 2014; Revised October 05, 2014; Accepted October 09, 2014

\begin{abstract}
Background: Men often play dominant role on decisions crucial to reproductive health but still they are at the back seat. In the past family planning programs have focused primarily on women because to free them from excessive child bearing. The aim of the study was to assess the involvement of men in family planning practices among male factory workers in Bahir Dar city. Methods: A cross sectional study was conducted in July 2013 among 306 male factory workers using simple random sampling technique. A pre-tested interview questionnaire was used to collect the data. The data were analyzed using bivariate and multivariate analysis with SPSS version 16 soft ware package. Results: The study revealed that $25.5 \%$ of male factory workers were involved in family planning practices. The study declared that educational status was a significantly predicts involvement on family planning (AOR=1.53, 95\% CI: 1.08-11.14, 1.8=95\% CI: 1.31- 9.220, and 2.01=95\% CI: 1.51-7.76). Besides, respondents who stayed in marriage from 4 to 13 years were about 18 times more likely to be involved on family planning compared to respondents stayed more than 22 years $(\mathrm{AOR}=18.06,95 \%$ CI: 1.79-58.68). Moreover, number of living children in a family was associated with an outcome of interest (AOR=11.01, 95\% CI: $1.13-106.9$ and AOR $=7.40$, 95\% CI: $1.49-36.64$ ) respectively. Conclusion: Only one out of four respondents involved in family planning. Besides, educational status, number of years in marriage, number of living children, and joint decision on the number of children were statistically significant predictors of male involvement on family planning. Therefore, ministry of health and all sectors concerned on reproductive health issues need to work on male involvement on family planning to regulate fertility and rapid population growth.
\end{abstract}

Keywords: family planning, male factory workers, bahir dar city, northwest ethiopia

Cite This Article: Yeshareg Walle, and Zelalem Alamrew, "The Current States of Male Involvement on Family Planning and Factors Correlated with among Male Factory Workers in Bahir Dar City.” American Journal of Public Health Research, vol. 2, no. 5 (2014): 188-197. doi: 10.12691/ajphr-2-5-2.

\section{Introduction}

Family planning services are crucial to promoting to decrease maternal and infant mortality. Expanding the availability of family planning services and working up on utilization of family planning services in developing countries could avert up to $42 \%$ of maternal deaths (Shazia A et al., 2010).

World fertility survey showed that utilization of family planning methods varied widely from 69\% south-east Asia to $11 \%$ in Africa (J E Darroch et al., 2013).

It is evident that the widespread adoption of family planning represents one of the most dramatic changes of the 20th century. The growing use of contraception around the world has given couples the ability to choose the number and spacing of their children, which, in turn, has prevented large numbers of unintended pregnancies and their consequences. Despite all of these impressive gains, contraceptive use is still low and the need for contraception is high in some of the world's poorest places (PRB, 20123).

Evidences showed that there high unmet need for contraceptive use in most developing countries and even higher in sub-Saharan countries where number of women with unmet need for modern contraception increased from 31 million in 2008 to 36 million in 2012 (UNFPA, 2012).

Ethiopia is the second most populous country in Africa with population growth rate of $2.9 \%$. The current population size of the country is greater than 82 million. The country has high total fertility rate (5.4 children per women), and a high maternal and infant mortality. Despite high population growth rate of the country evidences showed that Contraceptive prevalence rate of the country is very low which is $28.6 \%$ (Index mundi, 2014).

In Ethiopia experience over the last couple of decades has shown that as human numbers increased, the population carrying capacity of the environment decreased. A high population growth rate induces increased demand for resources and the rate at which these resources are 
exploited. In the country, where technology has not kept pace with the demands for greater productivity, environmentally harmful and economically counterproductive methods of exploiting land and associated resources are resorted to in order to meet immediate needs. As a consequence of this, climatic conditions are becoming erratic and soil quality is declining at an alarming rate (Melaku Demissie, 2007).

In Ethiopia population growth rate is not in line with the development of health services and other basic infrastructures. Hence, for the population growth to be compatible with the living standard of the people, family planning service should be promoted in the country. Besides, family planning is a good contributor to create sustainable and efficient use of the country's resources (CSA, ORC M, 2006).

Family planning was considered as a taboo before the adoption of the population policy in the country. The Ethiopian population policy on its health wing mainly focuses in the primary health care approach which has health education, education in personal and environmental hygiene, nutrition, immunization and family planning for standard components (NPEAE, 1993). But as a result of interventions by different actors, the cultural and social prejudices against the services is getting reduced significantly though still with low contraceptive usage (29\%); high unmet need and high rates of unwanted pregnancy and its complications (CSA, ORC M, 2006) knowledge gaps; fear of side effects, opposition by husbands or other family members, limited choice of methods, limited access and availability of services and poor quality of services are some of the barriers in meeting contraceptive needs (J E Darroch et al., 2013).

The unmet need for family planning remains high, with one in four currently married women not able to meet their FP needs, while overall awareness of FP methods is high, 87\% (Bongarts J, 1995).

In the past, family-planning programs have focused attention primarily on women, because of the need to free women from excessive child-bearing, and to reduce maternal and infant mortality through the use of modern methods of contraception despite child bearing is the outcome of both partners in a conjugal union and men together with women play key roles in reproductive health decision making. Most of the family-planning services were offered within maternal and child health (MCH) centers, most research and information campaigns focused on women with the assumption that women are the ones who bear child. This focus on women has reinforced the belief that family planning is largely a woman's business, with the man playing a very peripheral role (John C, 1990). Many men in Sub-Saharan African countries play an influential role in most household decision making. The social structure in most of these countries is patriarchal (Doddo F, Amoo N, 1998, Andongo BP et al., 1997).

Women also recognize the important role their husbands play in making various household decisions including reproduction (Toure L, 1996, Mary Chuwa, 2012) Studies on family planning in developing countries have long focused on women as the subject of interest. Very little work in this area has focused on men. It is now increasingly recognized that the actions required to achieving improvements in reproductive health outcomes in general and maternal health in particular should also encourage men's active participation (Arwen Bunce, 2007).

The past two decades witnessed an accelerated effort among researchers especially in developing countries to focus on couples as a means of understanding aspects of fertility such as family planning behavior (Bongarts J, 1995, Doddo F et al., 1998, Eliz, Chika A 1993) This is because of recognizing the fact that decisions regarding child birth with in marriage rest only with women but more frequently with both partners of a couple (Eliz, Chika A, 1993).

Male involvement in family planning (FP) means more than increasing the number of men using condoms and having vasectomies; it also includes the number of men who encourage and support their partner and their peers to use FP and who influence the policy environment to be more conducive to promoting male-related programs. In this context "male involvement" more than male contraception, and should refer to all activities aimed at men as a discrete group which have the objective of increasing the acceptability and prevalence of familyplanning practice of couples (Toure L, 1996).

\section{Materials and Methods}

Cross-sectional quantitative study design was conducted from July 24 to 302013 among male factory workers in Bahir Dar city at a distance of 563 kilometers from Addis Ababa, in the Northwestern part of Ethiopia. The city has nine kebele administrations. The word kebele is the smallest administrative units in a certain region of the country. There are seven major factories; the city has one governmental referral hospital, two private hospitals, thirty two governmental health centers and 33 pharmacies and drug stores.

All male factory workers in Bahir Dar city were our source population from which our study participants were selected.

Sample size of the study was determined using the single population proportion formula. The proportion of male's involvement on family planning was determined based on previous study of 23.7 \% (Alemayehu B, 2012). The following assumptions were used: level of confidence $95 \%$, a $5 \%$ marginal error. Based on these assumptions, the sample size was calculated as:

$\mathrm{n}=(\mathrm{Za} / 2)^{2} \mathrm{p}(1-\mathrm{p}) / \mathrm{w}^{2}$. Where; $\mathrm{n}=$ the minimum sample size needed, $\mathrm{P}=$ proportion of male's involvement of family planning $(23.7 \%), \mathrm{w}=$ absolute precision $=0.05$ and $\mathrm{Za} / 2=1.96$ at confidence level 95\%. Then, $\mathrm{n}=$ $(1.96)^{2}(0.237 \times 0.763) /(0.05)^{2}=n=278$. The final sample size with $10 \%$ non response rate came up with 306

\subsection{Sampling Technique}

The list of employee was obtained from each of the factories in the city. So that the respondents were selected from sampling frame prepared through simple random sampling technique.

\subsection{Data Collection Instrument and Measurement}


Data were collected using face to face interview structured questionnaires. The questionnaire was adopted from reviewed literatures (Alemayehu B, 2012, Yigzaw Kebede, 2000, Fasil Haile, 2006). The questionnaire was initially prepared in English and translated in to local language Amharic in order to obtain the required information from the respondents and was translated back to English to check for any inconsistencies. Training was given to data collectors and supervisors. Besides, pre-test was done and necessary modifications were done to questionnaire.

The outcome measure of this study was male involvement on family planning. Males said to be involved on family planning, if men accepted and indicated support to their partners' needs, choices and rights in reproductive health; or men's own used contraceptives such as condom, periodic abstinence, withdrawal and vasectomy either to space or stop births.

Data were double-entered onto the EPI-data Version 3.1 software by defining legal values for each variable and setting skip patterns. The double-entered data were validated and exported to SPSS version 16 software package.

\subsection{Data Processing and Analysis}

Univarate and bivarate analysis were computed to see the frequency distribution and to test whether there is association between male involvement on family planning and selected independent variables.

Factors associated with male involvement at bivariate were identified and the variables with p-value of 0.20 and less were taken to multivariable analysis and the model was built with backward elimination. In order to check the model fitness, Hosmer-Lemshow goodness of fit was applied ( $\mathrm{P}>0.05)$ and case wise listings of residuals were used to check outliers. Finally, the p-values less than 0.05 were considered statistically significant.

\subsection{Ethical Considerations}

Ethical clearance was obtained from Ethical review committee of Gondar University and communicated with regional health bureau before the time of data collection.

Letter of permission was obtained from the health bureau and each factory. The data were collected after securing informed consent from every respondent of the study.

\section{Results}

\subsection{Socio-demographic Characteristics of Male Factory Workers in Bahir Dar City}

According to this study, a total of 306 male factory workers were interviewed, resulting response rate of $100 \%$. The study declared that out of the total respondents $30.1 \%$, 22.2 , and $27.5 \%$ of them were in the age range of less than 23, 23 to 30 and 31 to 45 years and the remaining $20.3 \%$ of the participants were in age ranges of above 45 years.

Regarding marital status of the study participants, 180 (58.8\%) were married and 116 (37.9\%) were single. Besides, the study indicated that $95.8 \%$ of the respondents were orthodox Christian followed by $3.6 \%$ of the study participants were Muslim and the remaining small percents were from other religious group. Regarding educational status of the respondents $35.9 \%$ were $7^{\text {th }}$ to $10^{\text {th }}$ grade complete and $32.7 \%$ of respondents were diploma and above holders (Table 1).

\begin{tabular}{|c|c|c|}
\hline Variables(N= 306) & Categories & Total N (\%) \\
\hline \multirow{4}{*}{ Age } & $<23$ & 92(30.1) \\
\hline & $23-30$ & $68(22.2)$ \\
\hline & $31-45$ & $84(27.5)$ \\
\hline & $>45$ & $62(20.3)$ \\
\hline \multirow{3}{*}{ Marital status } & Single & 116(37.9) \\
\hline & Married & 180(58.8) \\
\hline & Divorced & $9(2.9)$ \\
\hline \multirow{3}{*}{ Ethnicity } & Amhara & $290(94.8)$ \\
\hline & Other & $16(5.2)$ \\
\hline & Orthodox & 293(95.8) \\
\hline \multirow[t]{5}{*}{ Religion } & Muslim & $11(3.6)$ \\
\hline & Other (Protestant) & $2(0.6)$ \\
\hline & Illiterate & $5(1.6)$ \\
\hline & Can read and write & $5(1.6)$ \\
\hline & Grade 1-6 & $47(15.4)$ \\
\hline \multirow[t]{5}{*}{ Educational status } & Grade 7-10 & $110(35.9)$ \\
\hline & Grade 11-12 & $39(12.7)$ \\
\hline & Deploma & $37(12.1)$ \\
\hline & Degree and above & $63(20.6)$ \\
\hline & $<4$ & $49(26.5)$ \\
\hline \multirow{4}{*}{ Number of years lived with marriage } & $4-13$ & $46(24.9)$ \\
\hline & $14-22$ & $46(24.9)$ \\
\hline & $>22$ & $44(23.7)$ \\
\hline & $<34.21$ & $78(25.5)$ \\
\hline \multirow{3}{*}{ Income category of respondents in USD } & $34.21-40.78$ & $78(25.5)$ \\
\hline & $40.8-52.63$ & $77(25.2)$ \\
\hline & $>52.63$ & $73(23.9)$ \\
\hline \multirow{2}{*}{ Employment status of partners $(n=184)$} & Employed & $59(32.06)$ \\
\hline & Non employed & $125(67.93)$ \\
\hline
\end{tabular}

The findings of this study further explored that concerning handling money and decision on the properties of the family indicated that about $43 \%$ and $81.7 \%$ of the respondents were handled money and decide on prosperities by both heads of the family (husband and wife). In addition regarding raring children and 
performing domestic activities of the household, the study indicated that $65.2 \%$ and 25.3 of respondents were raring children by both household heads of the family and the wife of the family respectively. $53.3 \%$ and $35.2 \%$ of respondents were reported to perform the domestic activities of the family by wife and both household heads of family respectively (Table 2).

Table 2. Decision making and empowerment of male factory workers in Bahir Dar city, Northwest Ethiopia, 2013

Handle money in family(n= 179)

Have decision power on properties $(n=180)$

Responsible for raring children( $\mathrm{n}=158)$

Who perform domestic activities $(\mathrm{n}=180)$
Category

Husband

Wife

Both

Husband

Wife

Both

Husband

Wife

Both

Other family member

Husband

Wife

Both

Other family member

Total $(\mathrm{N})$

$33(18.5)$
$69(38.5)$
$77(43.0)$

$18(10.0)$
$13(7.2)$
$147(81.7)$
$7(4.43)$
$40(25.3)$
$103(65.2)$
$8(5.07$
$2(1.1)$
$97(53.9)$
$62(34.4)$
$19(10.5)$

when and how many children to have; surprisingly about $18 \%$ of respondents reported that the decision was made by the husband only and only $1 \%$ of our respondents reported that the decision when and how many children to have was made by the wives. Accordingly, about $78.8 \%$ of our study participants reported that the decision when to stop child bearing was made by both husband and wife on discussion. Whereas about $12.9 \%$ of respondents responded only the decision was made by the husbands and only $5 \%$ of the respondents reflected that the decision when to stop is up to the decision of the women only.

Besides, this study explored that about 53\% of the respondents were need to have children in the future, out of which $23 \%$ were intended to have just right now, $14 \%$ were intended to have after 2 to 3 years and $21.2 \%$ were need to have children after 4 years from now (Table 3 ).

The finding of our study on the decision of having children indicated that about $80.7 \%$ of respondents reported that both husband and wife made the decision

Table 3. Reproductive history of male factory workers in Bahir dar city, Northwest Ethiopia, 2013

\begin{tabular}{|c|c|c|}
\hline Variables & Categories & Total N (\%) \\
\hline \multirow{4}{*}{ Number of living children $(n=190)$} & 0 & $31(16.3)$ \\
\hline & $1-2$ & $74(40.0)$ \\
\hline & $3-5$ & $68(35.8)$ \\
\hline & $>5$ & 17(7.9) \\
\hline \multirow{4}{*}{ Desired number of children(306) } & $<2$ & $134(43.8)$ \\
\hline & $2-3$ & $73(23.9)$ \\
\hline & 3- 4 & $62(20.3)$ \\
\hline & $>4$ & $37(12.1)$ \\
\hline \multirow{5}{*}{ Decision on number of children(187) } & Husband & 18(9.62) \\
\hline & Wife & $2(1)$ \\
\hline & Both & $151(80.74)$ \\
\hline & Husbands parents & $1(0.53)$ \\
\hline & God knows & $15(8.02)$ \\
\hline \multirow{3}{*}{ Need for additional children(200) } & Yes & $106(53.0)$ \\
\hline & No & $88(44.0)$ \\
\hline & We didn't decided & $6(3.00$ \\
\hline \multirow{5}{*}{ When to add children(113) } & Right now & $26(23.0)$ \\
\hline & 2-3years & $16(14.2)$ \\
\hline & 3- 4 years & 18(15.93) \\
\hline & After 4 years & $24(21.23)$ \\
\hline & I don't know & $29(25.66)$ \\
\hline \multirow{5}{*}{ Decision made when to have children(155) } & Husband & $8(5.16)$ \\
\hline & Wife & $9(95.81)$ \\
\hline & Both & $121(78.06)$ \\
\hline & We didn't decided & $6(3.87)$ \\
\hline & God knows & 11(7.09) \\
\hline \multirow{5}{*}{ Decision when to stop child bearing(179) } & Husband & $23(12.85)$ \\
\hline & Wife & $9(5.02)$ \\
\hline & Both & 141(78.77) \\
\hline & We didn't decided & $3(1.67)$ \\
\hline & God knows & $3(1.67)$ \\
\hline
\end{tabular}




\subsection{Knowledge of Contraceptive Use among Male Factory Workers in Bahir Dar city Northwest Ethiopia, 2013}

The findings of this study revealed that out of ten knowledge indicator questions asked respondents who answered 80\% correctly were 199 (65\%) and the rest 107 (35\%) of respondents answered less than $80 \%$ of the questions. 97.7\% of respondents ever heard of about family planning methods. Based on the response given where they got information regarding family planning $38.3 \%, 82.3 \%, 64.6 \%, 47.6 \%$ and $54.6 \%$ of the study participants were reported from friends, TV, health workers, health facility and books/reading materials respectively. Accordingly, the study declared that $97 \%$ of respondents knew methods to delay or avoid pregnancies.

According to the current study based on the questions asked on the assessment of knowledge of contraceptive methods $98 \%$, $83.1 \%, 96.7 \%, 90 \%, 96.3 \%$ and $38.7 \%$ of respondents reported that they knew about oral contraceptives, IUCD, injectables, implant, condom, and vasectomy respectively. Moreover, 44.3\%, 74.3\%, 46.7\% and $68.3 \%$ of the study participants were reported to know Tubal ligation, calendar method, breast feeding and withdrawal methods respectively as family planning methods.

Besides, the findings of this study revealed that only $2.4 \%$ of respondents believe that condom will not prevent pregnancy but the rest $97.6 \%$ of respondents perceive condom can prevent pregnancy. Moreover, $64.7 \%$ of respondents reported pregnancy might resulted after vasectomy, in addition $21.6 \%$ of respondents raised that vasectomy could result reduction in sexual feeling and $13.8 \%$ of the respondents of this study declared vasectomy had nothing effect.

In addition, the findings of this study declared that, $36.6 \%$ of respondents admitted that the advantage of having children was to get support during old age, 28.9\% mentioned the advantage having children was children were the source of happiness and $12.8 \%$ respondents reported having children was children were source of labor for the help of family (Table 4).

Table 4. Knowledge of contraceptive use among male factory workers in Bahir dar city northwest Ethiopia, 2013

Knowledge indicators

Ever heard of family planning(305)

Source of information(300)

Know any method to delay/avoid pregnancy (305)

Contraceptive methods known(300)

Attitude towards vasectomy(116)

Over all knowledge of contraceptive use(306)
Categories

Total n (\%)
Yes

No

Friends as source of information

TV as source of information

Health worker as source of info

Health facility as source of info

Books/journals as source of info

Yes
no
OCP
IUCD
Injectables
Implant
Condom
Vasectomy
Tubal ligation
Calendar or rhythm
Breast feeding
Withdrawal
Prevents Pregnancy
Reduce sexual feeling
No effect

Yes

No
298(97.7)

7(2.3)

115(38.3)

247(82.3)

194(64.6)

143(47.6)

1649(54.6)

296(97.0)

5(3.0)

294(98.0)

245(83.1)

290(96.7)

270(90.0)

289(96.3)

116(38.7)

133(44.3)

223(74.3)

140(46.7)

205(68.3)

75(64.7)

25(21.6)

16(13.8)

199(65.0)

107(35.0)

\subsection{Attitudes towards contraceptive methods among male factory workers in Bahir Dar city, Northwest Ethiopia, 2013}

The findings of this study declared that still 276(91.4\%) of the respondents reported that they need to know more about family planning both to avoid and delay pregnancy. The study also indicated that $97.4 \%$ of the respondents reported they approve family planning for couples. Besides, the respondents reported reason for approval of contraceptive use for couples was that about 94.6\%,
19.5\%, 59.5\%, 40\%, 43.4\% and 33.3\% of respondents reported to space birth, achieved desired family size, prevent unintended pregnancy, for health of mother and children, and drug side effect were the reason for the approval of family planning. However, there were study subjects who were disapproved contraceptive use for couples and these individuals were reasoned out for disapproval. Out of individuals who disapproved to use family planning $33.3 \%$ and $83.3 \%$ of respondents disapproved because of side effect and religious reasons respectively (Table 5). 
Table 5. Attitudes towards contraceptive methods among male factory workers in Bahir Dar city, Northwest Ethiopia, 2013

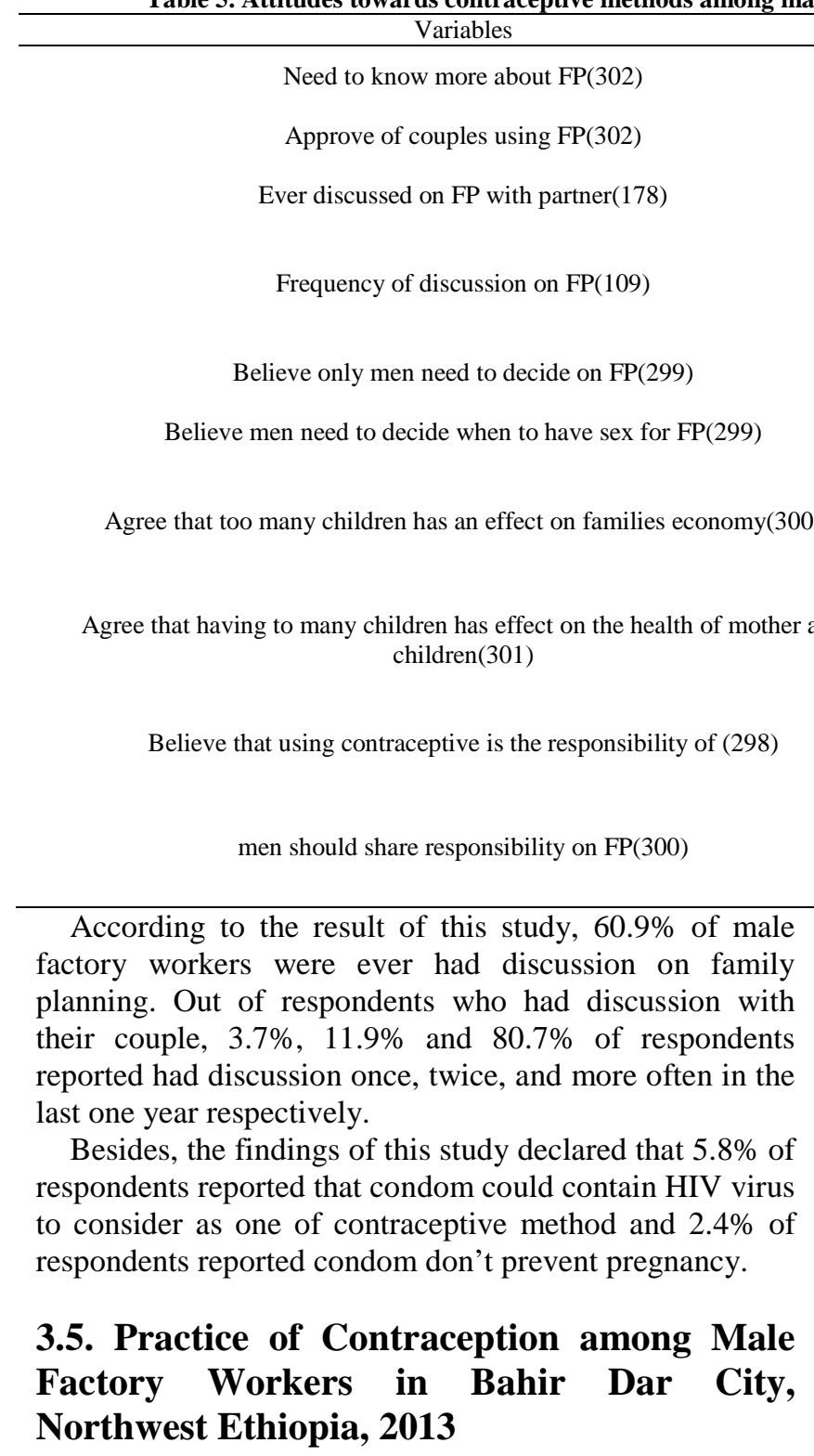

The findings of this study declared that about 78(25.5\%) of respondents were involved on family planning. The study also showed that $70 \%, 14.2 \%$ and $15.4 \%$ of our study subjects were new user, ever user and none user respectively. The study also indicated that $35.7 \%$, 25\%,

\begin{tabular}{cc} 
Categories & Total N $(\%)$ \\
Yes & $276(91.4)$ \\
No & $26(8.6)$ \\
Yes & $294(97.4)$ \\
No & $8(2.6)$ \\
Yes & $109(60.9)$ \\
No & $69(39.1)$ \\
Once & $4(3.7)$ \\
Twice & $13(11.9)$ \\
More often & $88(80.7)$ \\
I don’t member & $3(2.8)$ \\
Yes & $4(1.4)$ \\
No & $295(98.6)$ \\
Yes & $5(1.8)$ \\
No & $294(98.4)$ \\
Strongly agree & $272(90.6)$ \\
Agree & $20(6.6)$ \\
Disagree & $4(1.3)$ \\
Strongly disagree & $4(1.3)$ \\
Strongly agree & $219(72.8)$ \\
Agree & $45(14.9)$ \\
Disagree & $22(7.3)$ \\
Strongly disagree & $15(5.0)$ \\
Husband only & $76(25.5)$ \\
Wife only & $2(0.7)$ \\
Both & $220(73.8)$ \\
Strongly agree & $251(83.7)$ \\
Agree & $36(12.0)$ \\
Disagree & $10(3.3)$ \\
Strongly disagree & $3(1.0)$ \\
\hline Of the resp &
\end{tabular}

$25 \%$ and $14.3 \%$ of the respondents reported stopped using contraceptives after having less than 2, from 2 to 3,4 to 5 and greater than 5 children respectively.

Among respondents who were using contraceptives during the study period that the greatest number of respondents $55.6 \%$ reported they were using injectables, the remaining $18.5 \%, 14.1 \%$ and $4.4 \%, 2.9 \% 2.2 \%$ and $1 \%$ of our study subjects were reported were currently using oral contraceptive pills, implants, condom, IUCD vasectomy and breast feeding methods respectively.

Regarding the decision made on the type of contraception currently in use, only less than $0.8 \%$ of respondents reported decided by the husband alone, and about $25.2 \%$ of respondents it was up to the wife only to decide the family planning in use. However the majority of the respondents $(71.8 \%)$ of them reported that it was decided by the joint decision between husband and wife and the rest $2.3 \%$ of respondents reported it was decided by the health professionals (Table 6).

Table 6. Level of male involvement and Practice of contraception among male factory workers in Bahir Dar city, Northwest Ethiopia, 2013

Variables

Type of contraceptive user(190)

Reason to stop contraceptive use(19)

Males involved on family planning(306)

\section{Categories}

New user

Ever user

Non user

I don't know

Medical problem

$\mathrm{B} / \mathrm{c}$ of less perception of risk of pregnancy



No
Total n (\%)

133(70)

27(14.2)

29(15.3)

1(0.5)

6(31.5)

12(63.2)

1(5.3)

$78(25.5)$

228(74.5)
The findings of the study further explored on the contraceptive practice of the respondents that respondents who were not using contraceptives were asked the reason that they were failed to do so and reported that about $21.7 \%, 17.4,4.3 \% 8.7 \%$ and $30.4 \%$ of respondents were not using contraceptives because of the need for more 
children, health problems, accessibility problems, less perceived risk for pregnancy and because of different other reasons.

\subsection{Logistic Regression Analysis between Male Involvement on Family Planning and Predictor Variables among Male Factory Workers in Bahir Dar City, North West Ethiopia, 2013}

Accordingly, variables such as, educational status, number of years stayed in marriage, occupation, monthly income, number of living children, who decides on the number of children and decision to stop child bearing, partners were exported in to multivariate logistic regression analysis. It was found that educational status, number of years stayed in marriage, number of living children, who decides on number of children, and decision to stop child bearing were remained in the condensed model.

According to the findings of this study educational status of the respondents was a significant predictors of male involvement on family planning, showing that as educational status of respondents increases, there showed an evidence of males involvement on family planning $(\mathrm{AOR}=1.53$, 95\% CI: 1.08-11.14, $1.8=95 \%$ CI: $1.31-$ 9.220, and 2.01=95\% CI: 1.51-7.76).

Besides, this study respondents who stayed in marriage from 4 to 13 years were about 18 times more likely to be involved in family planning compared to respondents stayed more than 22 years in marriage ( $\mathrm{AOR}=18.06,95 \%$ CI: 1.79-58.68).

The other factor associated with male involvement on family planning was number of living children, respondents who had no and 1 to 2 children were about 11 and 7 times more likely to be involved on family planning compared to individuals who had more than five children $(\mathrm{AOR}=11.01,95 \%$ CI: $1.13-106.9$ and $\mathrm{AOR}=7.40,95 \%$ CI: 1.49- 36.64) respectively.

Moreover, joint decision on the number of children was the other significant predictors of male involvement on family planning, showing that families who decides on the number of children by discussion between husband and wife was about six times more likely to be involved on family planning (AOR=5.74, 95\% CI: 1.58- 20.81) (Table 7).

Table 7. Logistic regression analysis of factors independently associated with involvement on family planning among male factory worker in Bahir Dar City, North West Ethiopia 2013 


\section{Discussion}

The findings of this study revealed that $25.5 \%$ of male factory workers were involved in family planning including utilizing contraceptives to limit fertility and decisions to be made on spacing or limiting births between their spouses. The findings of this study was slightly in line with the study done in south region of Ethiopia where $33 \%$ of respondents were involved on the decision when to use and what method of family planning method to use (Binyam B et al., 2011 23).

The finding was in line with a study under taken in Kenya where more than $27 \%$ of the respondents were involved regarding on the type contraceptive used both to space and limit pregnancies (Rachel L.S et al., 2013). Whereas the findings of the current study was not in accordance with a study conducted in Hawassa Town south Ethiopia where more than half (54\%) of the study participants reported that joint decision between the husband and wife was made on the type of method used, when to have and limit births [Tsedeke T, 2006). The difference could be attributed due to different reasons including socio cultural and the discrepancy may also be attributed to difference the study time.

Besides, the study was not supported by a study conducted in USA where out of the total males involved in the study (38\%) of them were reported that they were involved jointly with their partners on the decision made on family planning methods (Gisele Maynard-Tucker, 1994).

The findings of this study further explored regarding handling money at household level indicated that about $42.5 \%$ and $38.7 \%$ of the respondents were handled money by both heads of the family (husband and wife) and wife of the family respectively. Showing that about $40 \%$ of the money of the house hold controlled by the wife of the family; showing that females were getting the chance and caring out their responsibility on leading their role as a family head. This was in line with similar findings where in just over half the households, financial decision-making half-half process, shared equally between husband and wife. However, where one or the other takes the lead role, the women were equally or better qualified to handle these decisions (Richard Barrington, 2013).

In addition according to the current study the majority of the respondents (82\%) revealed that both husband and wife of the family decide on the properties of the household on discussion. This implies that women are getting their autonomy and developing equal right or decision-making power in all aspects of the household properties. This was supported by other evidences where women are more likely than men to be primary decision makers in the household domain (Melissa J et al, 2013).

According to the current study about $65 \%$ of the respondents were knowledgeable by answering $80 \%$ of knowledge indicator questions on contraceptives and family planning bounding questions correctly and the rest $35 \%$ of the respondents were regarded non knowledgeable based on their knowledge scores. A similar study done in Uganda declared that about $60 \%$ of the study participants had good knowledge on family planning and importance of contraceptive use as spacing and limiting births and the resultant outcome of population crises in the absence of family planning (Agatha Kafuko, 2008).

Regarding the attitude of the study participants towards contraceptive use, $97.4 \%$ of the respondents reported they approve family planning for couples. The study further explored the reason for approval of contraceptive use for couples among the respondents was that $94.6 \%, 19.5 \%$, $59.5 \%, 40 \%, 43.4 \%$ and $33.3 \%$ of respondents reported to space birth, achieved desired family size, prevent unintended pregnancy, for health of mother and children, and drug side effect respectively were the reason reported on the side of the study subjects. This was in line with different studies where males have positive attitude and approve family planning to check and limit the current high population growth (Macellina Yet al., 2010).

Implying that respondents had a positive attitude for contraceptives so that male study participants approve either to use contraceptives their own or support their wives to use contraceptives either to space or stop birth. Besides, based on their response it is possible to observe that they understood the importance of family planning.

According to the findings of this study educational status of the respondents was a significant predictors of male involvement on family planning, showing that as educational status of respondents increases, there showed an evidence of males involvement on family planning $(\mathrm{AOR}=1.53$, 95\% CI: 1.08-11.14, 1.8= 95\% CI: 1.319.220, and 2.01=95\% CI: 1.51-7.76). This is supported by different studies done elsewhere in Africa where education was significantly affects contraceptive use (Agyei WK, Migadde M, 1995, Tawiah EO, 1997).

Besides, the study respondents who stayed in marriage from 4 to 13 years were about 18 times more likely to be involved in family planning compared to respondents stayed more than 22 years in marriage $(A O R=18.06,95 \%$ CI: 1.79-58.68). The probable reason for the difference could be male individuals who were recently married and stayed only less than four years are relatively younger are most of them are educated since according to Ethiopian educational policy today is education for all specially the younger group was educated and could have the knowledge of contraceptive use to space and limit births to secure one's own economy and in addition elder individuals who stayed in a marriage for more than 22 years were less educated and could have less advantage of contraceptive use and their partners were almost be entered menopausal stage.

The other factor associated with male involvement on family planning was number of living children, respondents who had no and 1 to 2 children were about 11 and 7 times more likely to be involved on family planning compared to individuals who had more than five children $(\mathrm{AOR}=11.01,95 \% \mathrm{CI}: 1.13-106.9$ and $\mathrm{AOR}=7.40,95 \%$ CI: 1.49- 36.64) respectively. However, this is not in accordance with other studies where involvement on contraceptive was higher among individuals who had more children than had no or less children (T B Mekonnen et al, 2013, Abdurahman et al., 2014). The reason for the discrepancy to the current studies could be study participants who had no or had 1 to 2 children were younger, mostly educated and now a day contraceptive were available for free with different choice.

In addition, for currently married individuals living expense including child rearing was becoming difficult 
due to the current economical inflations in the country. These reasons could positively influence individuals who had less children to be involved on contraceptive use and jointly decide on family planning with their partners compared to individuals who had more children and mostly older. Besides, these individuals might secured their economy and less educated because of education was not as such expanded in the country and not an easy to get chance of education in the previous times.

\section{Conclusion}

According to the findings of this study the following conclusions were drawn:

- Male involvement on family planning among male factory workers is $25.5 \%$. Which means only one out of four being involved despite the communal nature of family planning for women and men

- Educational status improves the level of male involvement on family planning

- Discussion and join decision encourages male involvement on family planning of male factory workers.

Therefore, governmental organizations including ministry of health and all sectors concerned on reproductive health issues need to work on male involvement on family planning.

Promoting education and increasing the educational status of male individuals and the community as a whole by the concerned bodies.

Concerned bodies should give great attention on young people and young adults to enable them to have a joint decision on family planning between the husband and wives to increase involvement of males on family planning.

Special education or short term training on reproductive issues such as on family planning should be given for males to increase their knowledge make them take an active involvement on family planning in terms of both on the decision when, what to use, and either husband or wife to use contraceptives to space or stop births.

\section{Conflict of Interests}

Authors declared that they have no conflict interests.

\section{Authors' Contribution}

Y. Walle: Conceptualized the research problem, designed the study, conducted field work, collected data, analyzed data

Z. Alamrew: was involved in data analysis and prepared the manuscript for publication.

\section{Acknowledgments}

This study was funded by a Grant from Family Guidance Association of Ethiopia. The authors are grateful to all participants, data collectors, and supervisors of the study.

\section{References}

[1] Shazia A Khan, Zain Ul Amin, Fouzia, Samina Jadoon. A comparative trial of copper T 380 and $\mathrm{Cu} 375$ IUCD. Ayub Med Coll Abbottabad 2010; 22 (3): 185-187.

[2] J E Darroch, S Singh. Trends in contraceptive need and use in developing countries in 2003, 2008, and 2012: an analysis of national surveys. The Lancet 2013; 381 (9879): 1756-1762.

[3] The Faces of Unmet Need for Family Planning July 2012. [Accessed date 12/08/14]. Available from: http://www.prb.org/Publications/Articles/2012/faces-unmet-needfamilyplanning.aspx

[4] UNFPA East and Southern Africa June 2012. Unmet need for contraception rises in sub-Saharan Africa. [Cited date 2 Jan 2014], Available at: http://esaro.unfpa.org/public/public/cache/offonce/news/pid/11166 \%3Bjsessionid=7AFFB08FFBC87F5CAF4F485285689904.jahia0 1

[5] Index mundi. Ethiopian demographic profile 2013. Accessed on 27 January 2014. Available from: http://www.indexmundi.com/ethiopia/demographics_profile.html

[6] MELAKU DEMISSIE. Ethiopia: Business \& Economy: Consequences of Population Explosion, Global Warming 3 March 2007

[7] CSA, ORC M. Ethiopian Demographic and Health Survey 2005. Addis Ababa, Ethiopia, Calverton, Maryland, USA 2006.

[8] National Population Policy of Ethiopia, Addis Ababa, Ethiopia, Office of the Prime Minister, April 1993. [Accessed date 17/05/2013]. Available from: [http://cyber.law.harvard.edu/population/policies/ETHIOPIA.htm].

[9] Bongarts J, Bruce J. The causes of unmet need for contraception and the social content of services. Studies in Family planning 1995; 26 (2): 57-75.

[10] John C. Caldwell and Pat Caldwell. High fertility in subsaharan Africa. Scientific America 1990; 262 (5): 118-8.

[11] Doddo F, Amoo N. Men matters additive and interactive gendered preferences and reproductive behavior in India. Demography 1998, 35 (2): 229-42.

[12] Andongo BP, Phillips JF, Kajihara B and et al. Cultural factors constraining the introduction of family planning among the Kasenna-Nankana of North Ghana. Social science and medicine 1997; 45 (12): 1789-804.

[13] Toure L. Male involvement in family planning: A review of literature and selected program initiatives in Africa 1996.

[14] Mary Chuwa. Male involvement in Family planning practice. African Journal of Midwifery and Women's Health 2012; 6 (3): 132-138.

[15] Arwen Bunce Greg Guest, Hannah Searing. Factors Affecting Vasectomy Acceptability in Tanzania. International. Family Planning Perspectives Volume 33, Number 1, March 2007.

[16] Eliz, Chika A. The influence of spouses over each other's contraceptive attitudes in Ghana. Studies in Family planning 1993; 24 (3): 163-73.

[17] Warren C. Robinson and John A. Ross. The Global Family Planning Revolution: Three Decades of Population Policies and Programs. The World Bank 2007

[18] Khalifa AM. Attitudes of urban Sudanese men toward family planning. Studies in Family planning 1988; 19 (4): 236-43.

[19] Alemayehu Bayray. Assessment of male involvement in family planning use among men in south eastern zone of Tigray, Ethiopia. Scholarly Journal of Medicine 2012; 2 (2): 1-10.

[20] Yigzaw Kebede. Contraceptive prevalence and factors associated with usage of contraceptives around Gondar Town. Ethiop. J. Health Dev. 2000; 14 (3): 327-334.

[21] Fasil Haile Georgis. Assessment of Factors Influencing the Utilization of modern Contraceptive Methods among Women in the Reproductive Age Group in Angolela and Tera District, North Shewa Administrative Zone, Amhara National Regional State. Addis Ababa university school of graduate studies 2006.

[22] SAHLE SITA. Assessment of the magnitude and determinants of unmet need for family planning among currently married women in urban and periurban community in Awassa, southern Ethiopia. Addis Ababa university school of graduate studies 2003.

[23] Binyam B, Mekitie W, Tizta T and et al. Married women's decision making power on modern contraceptive use in urban and rural southern Ethiopia. BMC Public Health 2011, 11: 342. 
[24] Rachel L.S, Sara J.N, Maricianah O and et al. Overcoming Barriers to Family Planning through Integration: Perspectives of HIV-Positive Men in Nyanza Province, Kenya. Hindawi Publishing Corporation, Volume 2013.

[25] Tsedeke T, Wakgari D, Ahmed A and et al. The role of men in contraceptive use and fertility preference in Hossana Town, southern Ethiopia. Ethiop.J. Health Dev. 2006; 20 (3).

[26] Gisele Maynard-Tucker. Men's and Women's Reproductive and Contraceptive Decisions: A Case Study from Highland Peru. Working Paper \#248, October 1994.

[27] Richard Barrington. Why Mothers Should Play a Bigger Role in Family Finances. Accessed date November 18, 2013, Available at: http://www.huffingtonpost.com/richard-barrington/womenfamily-finance_b_3065219.html)

[28] Melissa J. Williams and Serena Chen. When "Mom's the Boss": Control Over Domestic Decision Making Reduces Women's Interest in Workplace Power. SAGE Journals 2013, 16 (6): 1-19.

[29] Agatha Kafuko. Report on the Qualitative Assessment of Community Based Approaches to Promote Smaller Families and Family Planning Among Men in Uganda. September 2008.
[30] Macellina Y, Titilayo C, Kayode T. and et al. Male Involvement in Family Planning Decision Making in Ile-Ife, Osun State, Nigeria. African Journal of Reproductive Health 2010; 14 (4): 45.

[31] Agyei WK, Migadde M. Demographic and sociocultural factors influencing contraceptive use in Uganda. J Biosoc Sci. 1995; 27 (1): 47-60.

[32] Tawiah EO. Factors affecting contraceptive use in Ghana. J Biosoc Sci. 1997; 29 (2): 141-9.

[33] T B Mekonnen, A Moges, B Mengesha. Assessment of family planning use and associated factors among people living with HIV in Addis Ababa, Ethiopia. The Lancet, Volume 382, Issue, Page S10, 3 November 2013.

[34] Abdurahman Mohammed, Desalegn Woldeyohannes, Amsalu Feleke and Berihun Megabiaw. Determinants of modern contraceptive utilization among married women of reproductive age group in North Shoa Zone, Amhara Region, Ethiopia. Reproductive Health 2014, 11: 13. 